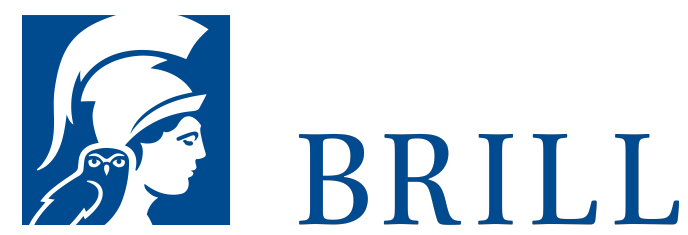

\title{
Gehirn, Geist und Bedeutung
}

Zur Stellung der Neurowissenschaften in der Leib-Seele-

Diskussion

Author: Robert Nitsch

Entgegen dem derzeitigen Selbstverständnis werden in diesem Buch die Beiträge der Neurowissenschaften zum Leib-SeeleProblem auf pragmatistische Weise eingegrenzt. Nach einer Rekonstruktion dieses Selbstverständnisses entlang der Searle'schen Position „brains cause minds“ wird ein exklusiver Zugang der Naturwissenschaften zur Lösung des Leib-SeeleProblems nach Sellars als Mythos entlarvt. Tatsächlich gelingt es den Neurowissenschaften nicht, das Gehirn und die ihm zugeschriebenen Leistungen innerhalb eines naturalistischen Forschungsprogramms zu fassen. Bewusstseinsphänomene sind nicht alleine auf physikalische Eigenschaften zurückzuführen, da Bedeutung nicht in allgemeinen Naturgesetzen der Physik beschrieben werden kann. Dem Konzept der Repräsentation der Welt im Gehirn wird das Programm eines semantischen Inferentialismus nach Brandom gegenübergestellt. Es schließt sich der Versuch an, nach Janich den Neurowissenschaften innerhalb der Leib-Seele-Diskussion einen Platz mittels pragmatistischer Positionen einzuräumen. Folgt man diesen Gedanken, ist die weitverbreitete Hybris der Neurowissenschaften gegenüber philosophischen Argumenten in der Leib-Seele-Diskussion zurückzuweisen.

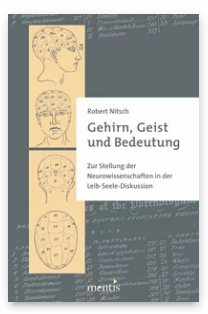

Pages: 166

Seiten

Language:

German

Subjects:

General,

Philosophy

Publisher: Brill | mentis

E-Book (PDF)

Released online:

o1 Dec 2012

ISBN: 978-3-

89785-961-6

List price

USD $\$ 52.00$

Paperback

Publication date:

o1 Dec 2012

ISBN: 978-3-

89785-794-о

List price

USD $\$ 52.00$ 
For more information see brill.com

Order information: Order online at brill.com +44330 333 0049 | customerservices@brill.com Submission information: brill.com/authors

Titles published by Brill | Fink, Brill | mentis or Brill | Schöningh: +49(o)715413279216| brill@brocom.de 